\title{
HIGH RESOLUTION MONOCHROMATOR SYSTEMS \\ USING THERMAL GRADIENT INDUCED VARIABLE BRAGG SPACING*
}

\author{
G. S. Knapp** and R. K. Smithert \\ **Materials Sclence and Technology Division \\ tChemical Technology Division \\ Argonne National Laboratory, Argonne, IL. 60439
}

\section{Distribution}

\begin{aligned} & \hline 1.-3. G. J. Hamilton \\ & 4. L. C. Iannie11o \\ & 5. F. Y. Fradin \\ & 6. H. B. Brodsky \\ & 7. B. R. T. Frost \\ & 8. F. A. N1chols \\ & 9. Ed1torial OEf1ce \\ & 10. D. J. Lam \\ & 11. G. S. Knapp \\ & 12. R. K. Smither \end{aligned}

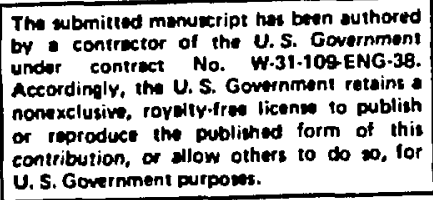


HIGH RESOLUTION MONOCHROMATOR SYSTEMS

USING THERMAL GRADIENT INDUCED VARIABLE BRAGG SPACING*

\author{
G. S. Knapp** and R. K. Smither $t$ \\ **Materials Sclence and Technology Division \\ tChemlcal Technology Divigion \\ Argonne National Laboratory, Argonne, IL. 60439
}

July 1985

\begin{tabular}{|c|}
\hline 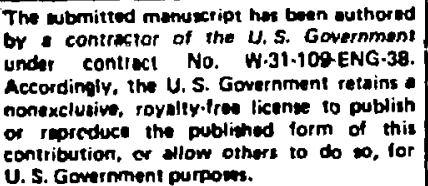 \\
\hline
\end{tabular}

*Work supported by the U. S. Department of Energy

Submitted to the International Conference on Synchrotron Radiation Instrumentation, Stanford, CA, July 29-August 2, 1985. 
HIGH RESOLUTION MONOCHROMATOR SYSTEMS

USING THERMAL GRADIENT INDUCED VARIABLE BRAGG SPACING*

\author{
G. S. Knapp*ᄎ and R. K. Smither $†$ \\ **Matertals Sclence and Technology Divistom \\ tChentcal Technology Division \\ Argonne National Laboratory, Argonne, IL. 60439
}

\title{
Abstract
}

The vertical divergences of bending magnet and wiggler synchrocron sources are generally consfderably larger than the acceptance angles of typlcal monochromator systems. This is particularly true at high energfes (E $\geq 14 \mathrm{keV}$ ) where the Darwin widths of perfect crystals are of the order $10^{-6}$ radians. By imposing a thermal gradient on the crystal, an efficient, wide acceptance angle monochromator can be obtalned. The necessary condition being that the resulting $d \cdot \sin \theta$ is a constant across the beam. Gains in Intensity of 3-100 can be realized relative to standard flat crystal systems. A number of posstble designs are presented for both two and four crystal monochromator systems. The use of $\mathrm{SI}, \mathrm{Ge}$, and quartz monochromators are discussed. 


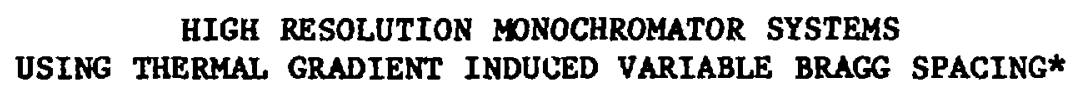

\author{
G. S. Knapp** and R. K. Smithert \\ **Materlals Sclence and Technology Division \\ tChemical Technology Division \\ Argonne Nat1onal Laboratory, Argonne, IL. 60439
}

Varlable d-spacing monochromators offer some interesting possiblifties for the designer of $x$-ray optlcal systems. The varlable spacing can be achieved in a number of ways including doping, strain, and thermal gradients.1 The use of thermal gradients seems to be the simplest and most precise method. By proper applicatior of a thermal gradient it is possible to match the acceptance angles of the monochromator to the vertical divergence of a synchrotron beam. Previously smither ${ }^{l}$ has discussed the use of thermal gradients for both flat and curved monochromator systems. We apply the ideas to certala synchrotron applications.

Darwin widths of perfect single crysatals are quite small, varying from 5 $x 10^{-5}$ to $10^{-6}$ radians, ( 1 sec to $0.2 \mathrm{sec}$ ) depending on the energy and orfentation of the crystals. The magnitude of the vertical openting angle, $\Delta \theta$, of bending magnet and wiggler beams is $1 / \gamma$ where $\gamma$ is the ratio of the beam energy to the rest mass energy of the electron. For the National Synchrotron Light Source (NSLS) this $1 \mathrm{~s}$ approximately $2 \times 10^{-4}$ radians.

In $\mathrm{fig}$. 1 we show a diagram of a two crystal beam Iine where thermal gradlents have been applied to both crystals, ("A" and "B"). The crystals have a thermal expansion coefficlent of " $\alpha$ " so that

$$
\frac{\Delta d}{d}=\alpha \Delta T
$$

where $d$ is the Bragg spacing, Ld the change in the Bragg spacing and $\Delta T$ is the varlation of temperature across the beam. Combining Eq. 1 with Bragg's law we get

$$
\Delta T=\frac{1}{\alpha} \frac{\Delta d}{d}=\frac{1}{\alpha} \cot \theta \Delta \theta
$$

*Work supported by the U. S. Department of Energy. 
The acceptance angles of the crystals will match the vertical divergance of the beam if eq. 2 is satisfied.

The heat, $W$, necessary to Impose this gradient is

$$
W=K A \frac{\Delta T}{\Delta I}
$$

where $K$ is the thermal conductivity of the crystal, A is the cross section area, and $\Delta l$ is the length of the beam across the crystal. If the source is a distance $L$ from the crystal then

$$
\Delta l=\frac{L \Delta \theta}{\sin \theta}
$$

By substitution we get

$$
\frac{\Delta \mathrm{T}}{\Delta \mathrm{l}}=\frac{\cos \theta}{\alpha \mathrm{l}}
$$

and

$$
W=K A \frac{\cos \theta}{\alpha L}
$$

Interestingly, the thermal gradients and heats are independent of the opening angle, oniy $\Delta r$ depends on 1 t.

The Darwin width of a perfect crystal depends on the materlal, energy and crystal orfentation. Here we are golng to discuss a number of different crystals and a number of orlentations so we wlll use the simple, approximate formulation of Berreman ${ }^{2}$. Ignorting absorption,

$$
\delta \theta=2\left|\frac{F_{\text {re }}}{F_{0}}\right| \frac{\left(1-N_{\text {re }}\right)}{\sin \theta \cos \theta}
$$

and

$$
\frac{E E}{E}=2\left|\frac{F_{0}}{F_{0}}\right| \frac{\left(1-N_{r e}\right)}{\sin ^{2} \theta}
$$

where $\delta \theta$ is the Darwin width, $\left|\frac{F_{\text {re }}}{F_{0}}\right|$ is the real part of atomlc scattering factor and $n_{r e}$ is the real part of the Index of refraction. The opening angle 
(FWHM) $^{3}$ of the synchrotron is

$$
\Delta \theta=\frac{0.94}{\delta}\left(\frac{\lambda}{\lambda_{c}}\right)^{0.425}
$$

where $\lambda$ is the wavelength of synchrotron light and $\lambda_{c}$ is the critical wavelength.

In $\mathrm{fig} .2$ we show the opening angle of NSLS (solid line) and the Darwin widths for a number of crystals at three energles $(5.41,8.05$, and 17.48 $\mathrm{keV}$ ). Note that at the low energles, the opening angles are only 3-10 times greater than the Darwin width whereas at the higher energies they are almost two orders of magnitude larger. The gain in intensity is the approximate ratio of the Darwin widths to $\Delta \theta$. In Table 1 we summarize the relevant parameters for a number of crystals. Note that in all cases the temperature differences, gradients, and heat loads are quite modest and should not provide difficult engineering challenges.

For high and ultra high resolution experiments a four crystal design of the type described by Heald ${ }^{4}$ seems supertor to the two cyrstal designs. Frum Table 1 it can be seen that the highest resolution is achleved using a $S 1(14,6,0)$ crystal. The gradients and heats required are quite small, consequently, It is clear that the white beam from the synchrotron must not be allowed to fall on this crystal. The beam heating would clearly detune the crystal. It seems that it would be better to use $S t(4,0,0)$ or $S t(8,4,0)$ crystals for the first (" $A$ " and " $B$ ") and the $S 1(14,6,0$ ) for the second palr ("C" and "D") (See Fig. 3). In certain applications quartz crystals have better resolution than St but they are generally not used because of thelr sensttivity to radiation damage. The radiation damage would be minlmized by using the four crystal design with $S 1$ crystals for the first palr (" $A$ " and " $B$ ") and quartz for the second (" $C$ " and "D"). Currently many beam lines are using sagittal focusing 5 to account for the horizontal divergence of bending magnet radiation. Nothing discussed above precludes such focusing. Only one crystal would need to be bent. Another approach 18 to bend the first crystal, " $A$ ", in the horizontal plane and apply a thermal gradient to it as shown in fig. 4. In this case, Smfther has shown that a parallel, monochromatic beam results. In fig. 4 we show one such arrangement, where the first crystal is followed by two flat high resolution crystals to further monochromatize the 
beam. The fourth, crystal " $D$ " is bent to obtaln sigittal focusing. A two crystal design would also work well.

The use of thermal gradients adds some complexity to the design of a beam 1ine. However, it results in certain simplifications. It eliminates the need for complex, expensive focusing mirrors. If harmontc rejection is needed a flat afrror will suffice. Plzoelectric positioners are also not needed since simple adjustment of the average temperature can bring a crystals reflection energy into colncidence with the other crystals. Temperatures can easily be measured and adjusted to hundreths of a degree, which allows energy adjustments of tenths of a meV.

The application of thermal gradients can be done in a varlety of ways. Perhaps the simplest is water or freon cooling at one and electrical heating at the other controlled by analog feedback systems. Considerable work will be required to develop the best methods. We plan to test some of these concepts at NSLS in the near future.

\section{Acknowledgments}

The authors would like to acknowledge helpful discussion with P. Georgopoulos, S. Heald, A. McKale, P. A. Montano, and G. Shenoy. 
Table 1

\begin{tabular}{|c|c|c|c|c|c|c|c|}
\hline Crystal & $E(\mathrm{keV})$ & $\Delta \mathrm{T}\left({ }^{\circ} \mathrm{K}\right)$ & $\frac{\Delta \mathrm{T}}{\Delta l\left(\mathrm{O}_{\mathrm{K} / \mathrm{cm}}\right)}$ & W(watts) & $\begin{array}{c}\delta(\theta) \\
\left(10^{-5} \text { radians }\right.\end{array}$ & $\delta \mathbf{E} \quad(m e V)$ & GaIn \\
\hline$s 1(1,1,1)$ & 5.4 & 212 & 323 & 162 & 6.7 & 920 & 3 \\
\hline$s 1(2,2,0)$ & 5.4 & 112 & 279 & 139 & 4.1 & 221 & 5 \\
\hline$S 1(4,0,0)$ & 5.4 & 53 & 187 & 83 & 3.6 & 125 & 6 \\
\hline $\operatorname{Ge}(2,2,0)$ & 5.4 & 48 & 114 & 28 & 7.4 & 569 & 3 \\
\hline Quartz $(2,0,1)$ & 5.4 & 22 & 52 & 2.6 & 1.32 & 100 & 15 \\
\hline Quartz $(3,1,0)$ & 5.4 & 1.8 & 7.7 & 0.4 & 6.34 & 41 & 3 \\
\hline$S 1(1,1,1)$ & 8.0 & 263 & 336 & 168 & 4.4 & 1,375 & 4 \\
\hline$s 1(4,0,0)$ & 8.0 & 100 & 285 & 143 & 1.6 & 187 & 10 \\
\hline$s \pm(6,2,0)$ & 8.0 & $\because$ & 154 & 77 & 1.6 & 62 & 10 \\
\hline $\operatorname{Ge}(4,0,0)$ & 8.0 & 51 & 116 & 29 & 2.6 & 326 & 8 \\
\hline Quartz $(2,0,3)$ & 8.0 & 23 & 53 & 13 & 1.2 & 145 & 16 \\
\hline Quartz $(2,4,2)$ & 8.0 & 0.6 & 2.4 & 0.6 & 5.0 & 14 & 4 \\
\hline$S \pm(4,0,0)$ & 17.5 & 182 & 335 & 167 & .66 & 417 & 18 \\
\hline $\mathrm{s} 1(8,4,0)$ & 17.5 & 68 & 282 & 140 & .14 & 33 & $87 *$ \\
\hline$S f(14, \dot{b}, 0)$ & 17.5 & 5.1 & 36 & 18 & .19 & 3.5 & $61 *$ \\
\hline $\operatorname{Ge}(8,5,0)$ & 17.5 & 29 & 112 & 28 & .24 & 63 & $48 *$ \\
\hline Quartz $(0,0,9)$ & 17.5 & 12 & 51 & 2.5 & .096 & 23 & $123^{*}$ \\
\hline
\end{tabular}




\section{Table Caption}

The relevant parameters (defined in the text) for virlous crystals at three different energles. The values were calculated assuming the crystals or 12 meters from the source, the crystals are $0,1 \mathrm{~cm}$ thick, $1 \mathrm{~cm}$ long and $5 \mathrm{~cm}$ wide. The thermal conductivities are $1,0.5$ and 0.1 watts $/ K-c m$ for $S t$, Ge and quartz respectively. The thermal expansion coefflclents are $2.4 \times 10^{-1}, 6 \times$ $10^{-6}$ and $13 \times 11^{-6} o_{K}^{-1}$ for $S 1, G e$ and quartz respectively.

*The gains in Intensity were calculated assuming a vanishing source size. For NSLS to source swize of $0.1 \mathrm{~mm}$ would $11 \mathrm{mlt}$ the galns to approximately 20 . 
References

1. R. K. Sm1ther Rev. Sc1. Instrum. 63 (1982) 131.

2. Jorkshop on $\mathrm{x}$-ray Instrumentation for Synchrotron Radlation Research H(SSRL Report No. 78/04) Ed. H. Wlntck and G. Brown (1978) II-1.

3. G. K. Green BNL Report \$50522 (1976).

4. S. M. Heald, Nucl. Instr. and Meth. 222 H(1984) 160.

5. G. E. Ice and C. J. Sparks Jr. Nucl. Instr. and Meth. 222 (1984) 121. 


\section{Flgure Captions}

FIg. 1 Schematic drawing of a two crystal system for monochromatizing a synchrotron beam. Both crystals are flat and have a thermal gradient applied to them so that the value of $d \sin \theta$ is a constant.

Fig. 2 A graph comparlng the opening angle solld line $g$ a synchrotron beam width with the Darwln width of varlous planes in Ge(squares), si(clrcles) and Quartz (trlangles).

F1g. 3 Schematic drawing of a form crystal system to monochromatize a synchrotrons beam. All four crystals have thermal gradients applled to them.

F1g. 4 Schemat1c drawing of a four crystal system to monochromatize and focus a synchrotron beam. Only crystal "A" has a thermal gradient. applied to 1t. 


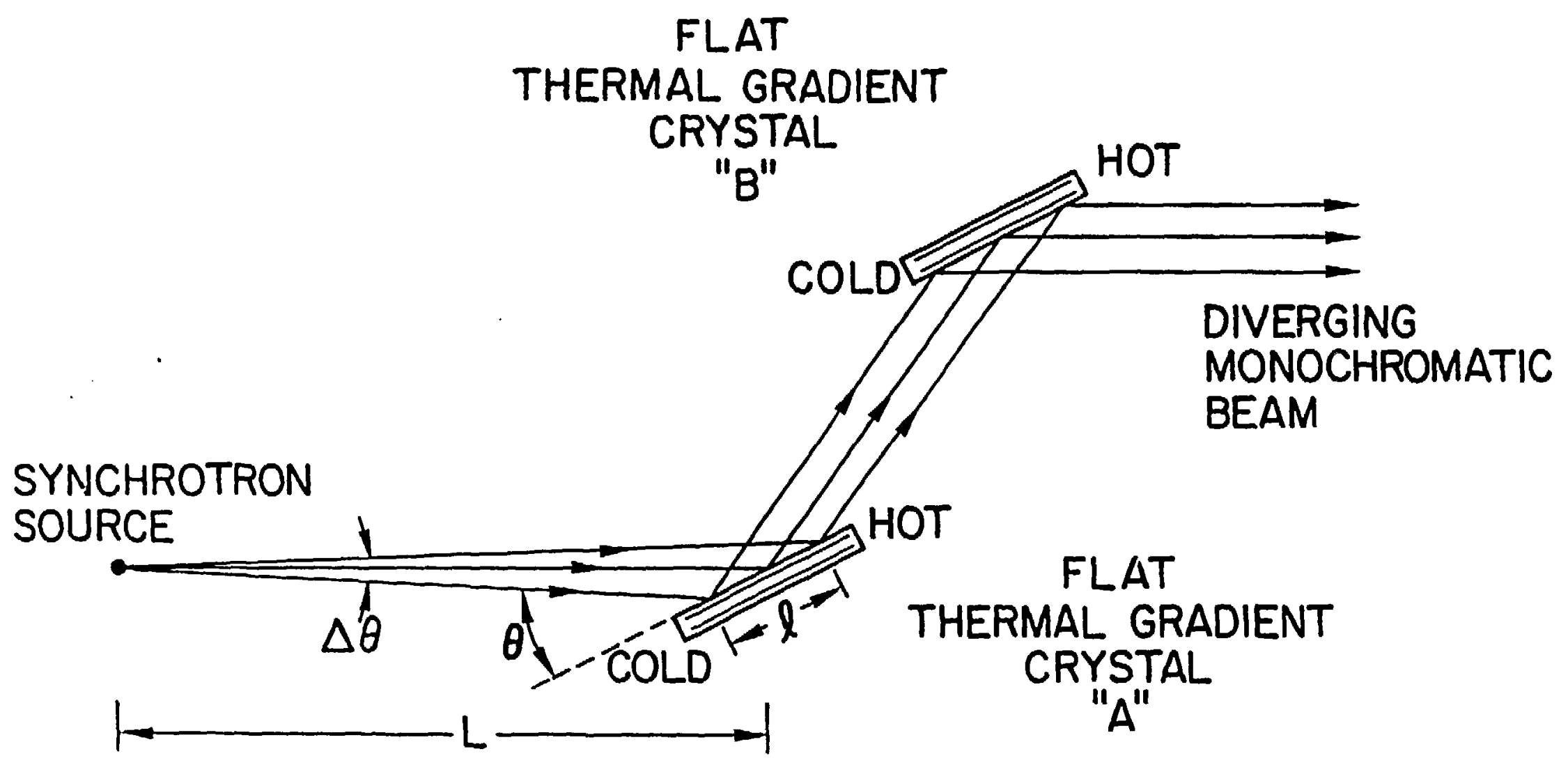


DARWIN WIDTH (FWHM)

" IN RADIANS

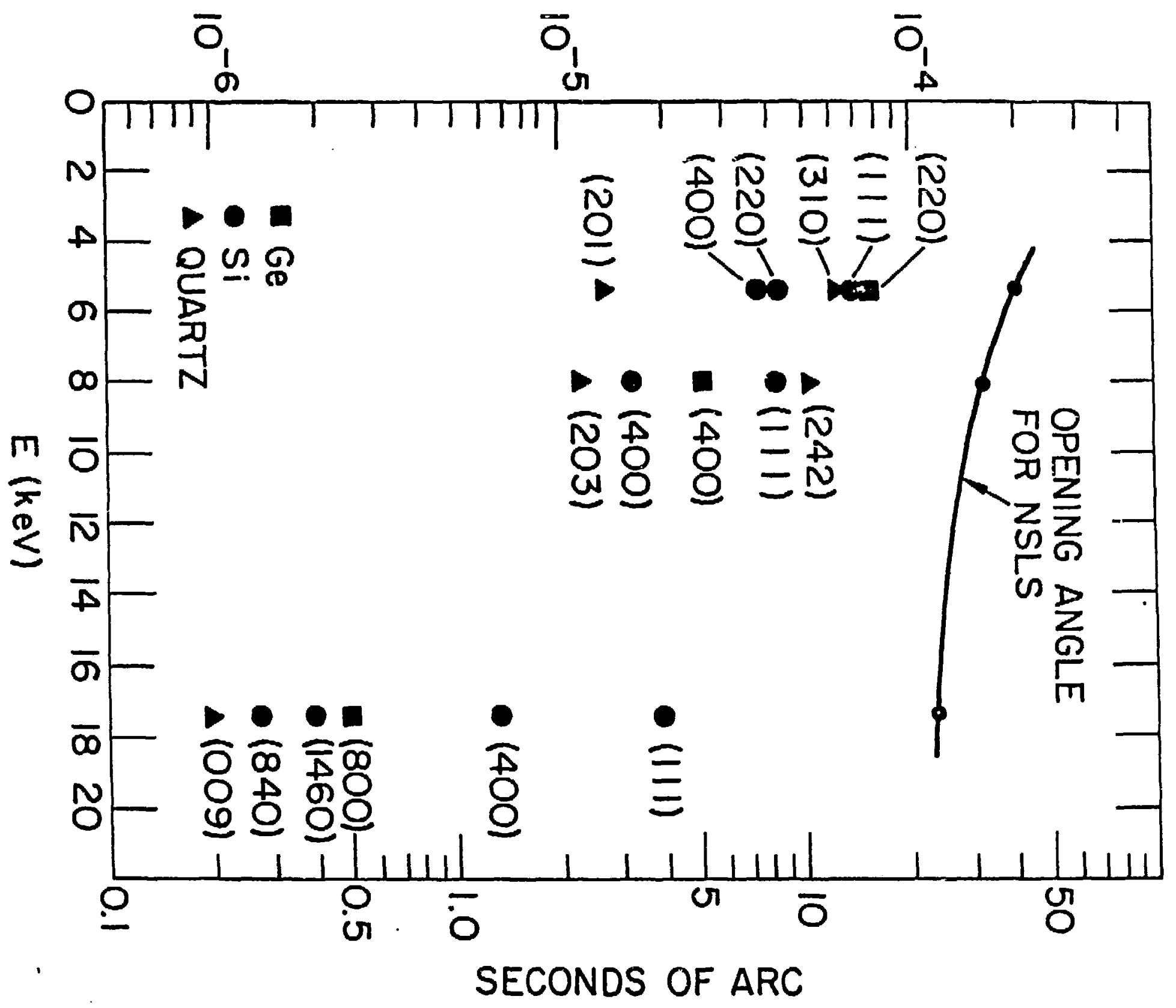




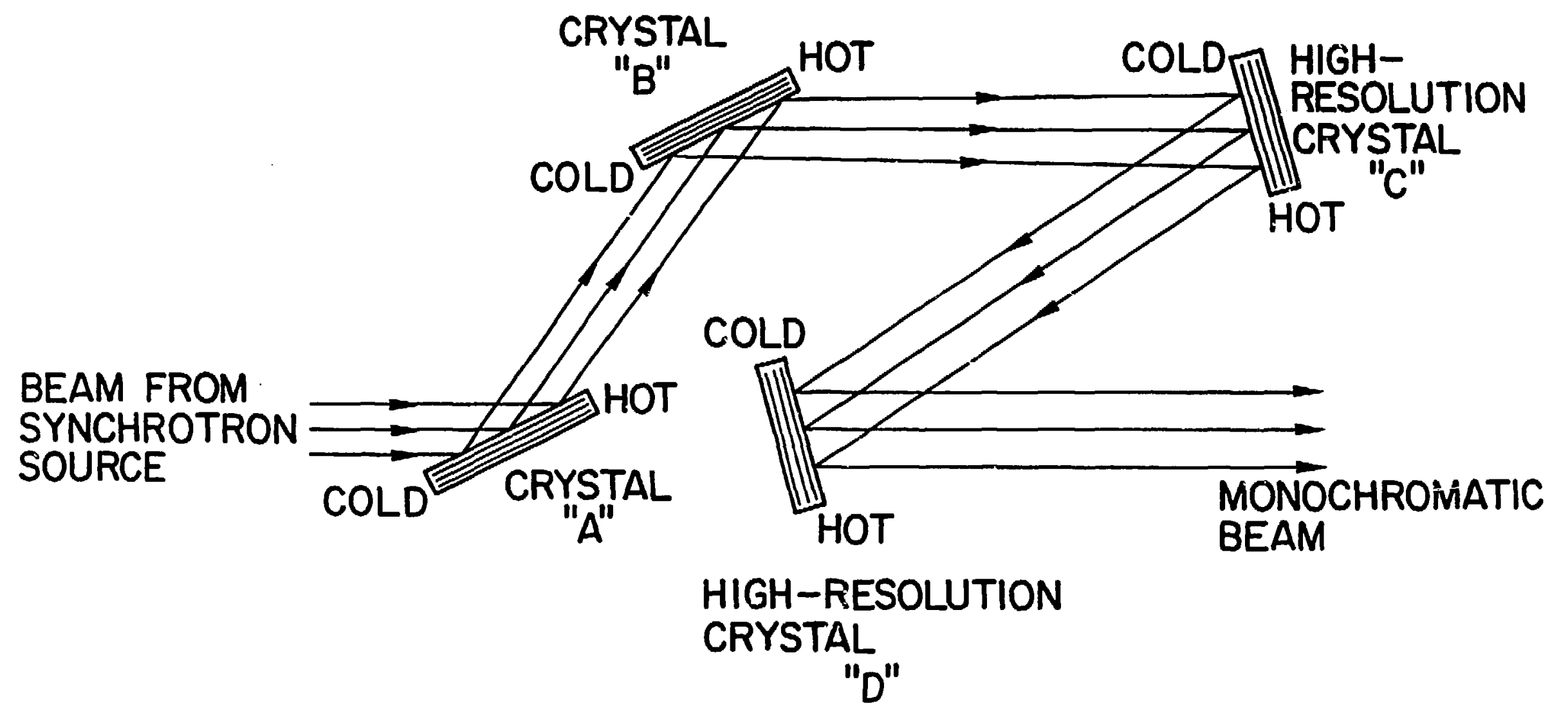




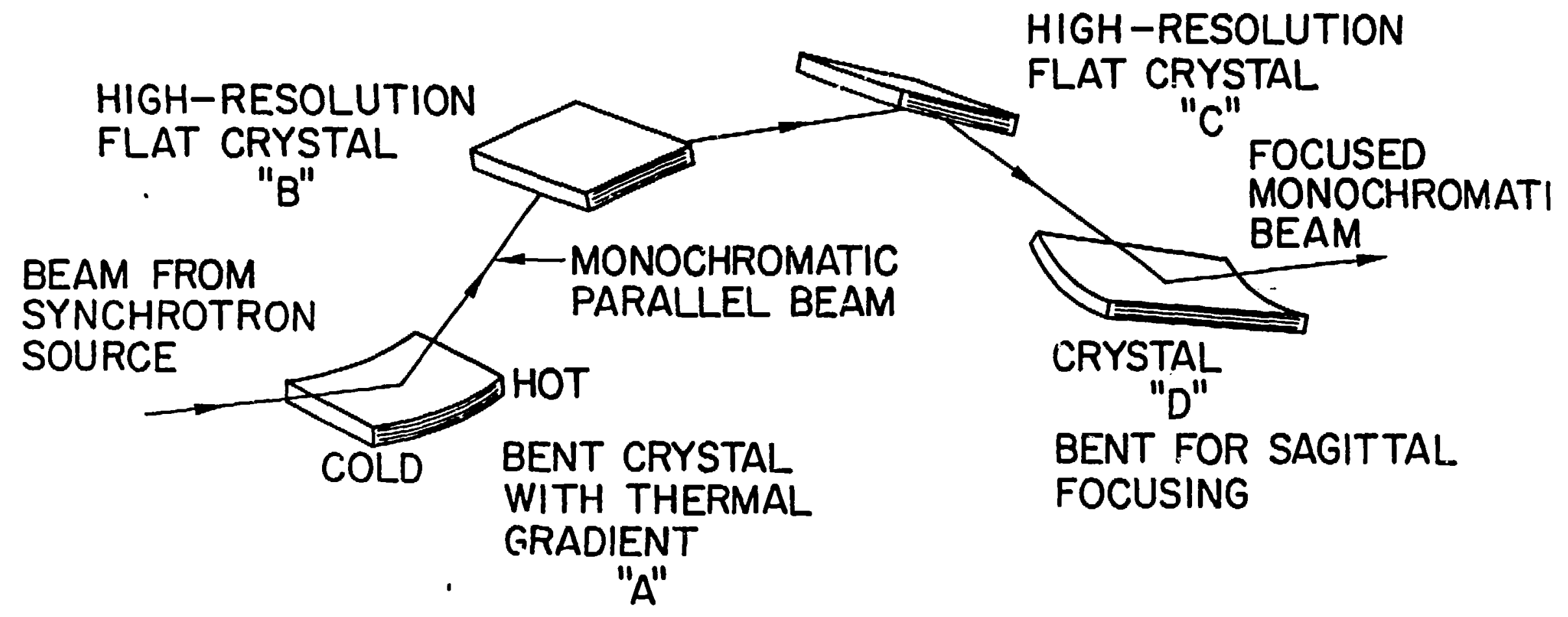

